\title{
Activity-dependent Retinotopic Refinement in a Low-Density Retinotectal Projection in the Goldfish: Evidence Favoring Synaptic Cooperation over Competition
}

\author{
Michael D. Olson and Ronald L. Meyer \\ Developmental and Cell Biology, Developmental Biology Center University of California, Irvine, California 92717-2275
}

\begin{abstract}
During optic nerve regeneration in goldfish, the label from a small retinal spot injection of WGA-HRP has been previously reported to be initially widely dispersed in the tectum and subsequently to condense into a small patch in the retinotopically appropriate location of tectum. This refinement involves two separate processes: one is activity independent and generates gross retinotopy; the other is activity dependent and mediates the formation of fine retinotopy. Since the number of synapses remains constant during this refinement, one or both of these processes may involve some form of competition for a limited number of synaptic sites.

To clarify the role of synaptic competition, we created a low-density retinotectal projection in goldfish by deflecting about $20 \%$ of the optic fibers from one tectum into the opposite tectum, which was denervated of all other optic fibers. Under this condition, it was previously shown that less than half the normal density of synapses is formed. If competition for synaptic sites is a requirement of refinement, refinement should be prevented or significantly hindered.
\end{abstract}

To monitor refinement during regeneration, $2 \mathrm{nl}$ spot injections of WGA-HRP were made into the retina at various times after deflection. To distinguish between activity-dependent and activity-independent refinement, retinal impulse activity was blocked in some fish with repeated injections of TTX into the eye for the duration of the experiment. It was found that considerable activity-independent refinement occurred under continuous TTX blockade although the fibers remained more dispersed than in previous TTX studies when normal numbers of fibers were present. Surprisingly, in fish with normal impulse activity, the degree of activity-dependent refinement was almost normal. Labeled fibers condensed into a small area roughly comparable in size to that observed when the full complement of fibers was regenerating into tectum. These results suggest that competition for limited synaptic sites is not essential for activitydependent refinement, which may, instead, be mediated by a cooperative process that actively promotes convergence. The findings further suggest that if synaptic competition plays a role in this system, it is in regulating activity-independent

\footnotetext{
Received Oct. 23, 1992; revised June 14, 1993; accepted June 30, 1993.

This work was supported by NIH Grant EY6746 to R.L.M

Correspondence should be addressed to Ronald Meyer, Developmental Biology Center, Biological Science 2, University of California, Irvine, CA 92717-2275.

Copyright $(1994$ Society for Neuroscience $0270-6474 / 94 / 140208-11 \$ 05.00 / 0$
}

mechanisms that determine the large-scale distribution of fibers within tectum.

[Key words: activity, regeneration, retinotectal, WGA-HRP, TTX, goldfish]

In goldfish, electrophysiological mapping (Meyer, 1977; Schmidt and Edwards, 1983) and various anatomical methods (Meyer, 1980; Meyer et al., 1985) have consistently demonstrated that severed optic fibers will regenerate back into the tectum to reform a highly topographic projection. This process is progressive. Fibers initially make large-scale errors but reestablish rough retinotopy by $30 \mathrm{~d}$ and by $60 \mathrm{~d}$ reform a projection that is nearly normal (Meyer, 1980; Meyer et al., 1985; Olson and Meyer, 1991a).

Two separate cellular processes have been proposed to mediate this retinotopic refinement, one activity independent, and the other activity dependent. Under continuous TTX blockade, optic fibers can reform a retinotopic projection in which largescale (quadrant level) errors have been largely eliminated but the degree of order is still crude, approximately that observed at $30 \mathrm{~d}$ when rough retinotopy is normally reestablished. This activity-independent refinement is thought to be mediated by chemoaffinity wherein fibers are guided to their appropriate destination by substrate markers in the optic pathway and on the tectum (Sperry, 1963). Under TTX blockade, however, the formation of highly ordered retinotopy is indefinitely inhibited such that at $120 \mathrm{~d}$, retinotopic order remains only slightly improved from that seen at $30 \mathrm{~d}$. This order can be inferred from the size of multiunit receptive fields (Schmidt and Edwards, 1983) and directly visualized by anatomical mapping methods (Meyer, 1983b; Olson and Meyer, 1991a).

A related series of studies on the formation of ocular dominance columns also points to two cellular processes. When optic fibers from both eyes are made to regenerate simultaneously into one tectum, the fibers from each eye form a projection that is roughly retinotopic and totally overlapping at about $30 \mathrm{~d}$ (Meyer, 1983a; Meyer and Kageyama, 1988). By 60 d, fibers from each eye are largely segregated into ocular dominance-like patches. This segregation, but not the general retinotopy, is completely prevented with activity blockade (Meyer, 1982; Olson and Meyer, 1991a). Similar findings have been obtained for development of visual projections in cats (Stryker and Harris, 1986; Shatz and Stryker, 1988; Swindale, 1988) and frogs (Reh and Constantine-Paton, 1985).

These findings have been interpreted to mean that optic fibers use impulse activity as a cue to form fine retinotopy. Neigh- 
boring retinal ganglion cells exhibit locally correlated activity (Arnett, 1978; Ginsburg et al., 1984), and it is generally supposed (see review, Udin and Fawcett, 1988) that growing fibers use this synchronous activity to identify which fibers to terminate with by following the rule: fibers that fire together, terminate together.

In goldfish, much of the retinotopic refinement entails extensive synaptic rearrangement. In an electron microscopic study in which optic fibers were labeled with HRP, normal numbers of synapses were found by $30 \mathrm{~d}$ and remained constant thereafter (Murray and Edwards, 1982; Hayes and Meyer, 1989a,b). This suggested that a fixed number of synaptic sites are filled early on in regeneration, and then these synaptic connections are extensively rearranged during the course of refinement. Subsequent ultrastructural work in which fibers from selected retinal regions were labeled has directly confirmed the existence of transient ectopic synapses that are progressively eliminated during refinement (Kageyama and Meyer, 1988; Meyer and Kageyama, 1988). The numerical constancy of optic synapses during regeneration appears to be dictated by the tectal target cells. When the posterior half of tectum is removed, forcing twice as many optic fibers into the anterior remnant, the number of synapses per unit tectal area remains normal (Murray et al., 1982; Hayes and Meyer, 1988a). Thus, on average each optic fiber must be making half as many synapses, while each tectal cell receives its normal complement. This implies that there is some characteristic "normal" number of synaptic sites on each tectal cell, and that optic fibers are normally capable of making more than this number but are constrained by the tectal target neurons. In other words, there is a fixed number of optic synaptic sites that are normally all filled. We will refer to this condition as "saturated synaptic sites."

This rearrangement of a fixed number of synaptic connections implies that competition for limited synaptic sites might be important for refinement, particularly for activity-dependent refinement, most of which takes place after $30 \mathrm{~d}$ when synaptic sites are filled. Additional evidence for competition in activitydependent refinement can be found in developmental studies on the mammalian visual system. When one eye was occluded at the time when ocular dominance columns were forming, the columns normally activated by the deprived eye were smaller while the columns normally activated by the nondeprived eye were expanded (Hubel and Wiesel, 1970; Hubel et al., 1977). This was interpreted to mean that more active fibers were better able to compete for synaptic space in visual cortex. To explain this further, Stent (1973) has presented a Hebbian model in which synapses that are inactive when the larget cell fires are replaced by "competing" neighboring fibers.

In spite of this seeming preponderance of evidence and opinion for competition in refining projections, few direct tests of it have been done. Indeed, an alternative to competition can be envisioned, namely, an activity-dependent cooperative process. Rather than synapses being subjected to a continuous displacement pressure as a result of fibers competing for the limited resource of synaptic sites, the synapses could be inherently unstable (short-lived) until preferentially stabilized by correlated pre- and postsynaptic activity. In other words, there could be an activity-dependent positive feedback signal that actively promotes the convergence of coactive synapses onto target cells without regard to the availability of alternative target sites.

In an effort to distinguish between competitive and cooperative processes, we have tested whether saturated synaptic sites are necessary for refinement. To do this, we created a lowdensity retinotectal projection in goldfish in which the number of synaptic connections was well below normal. This projection was formed by removing one eye so as to denervate one tectum of all optic fibers and then deflecting about $20 \%$ of the optic fibers from the opposite tectum into this denervated tectum. It was previously shown that under these conditions, optic fibers formed, at most, $40 \%$ of the normal number of synapses (Hayes and Meyer, 1988b). It was also shown that the number of nonoptic synapses in the main optic innervation lamina (stratum fibrosum et griseum superficiale, SFGS) is not affected by eliminating all optic fibers or by reducing or increasing their number, indicating that nonoptic fibers do not compete for optic synaptic sites (Murray and Edwards, 1982; Murray et al., 1982; Hayes and Meyer, 1988a,b). 'Thus, there should be significant numbers of "vacant," potential synaptic sites on tectal cells available to optic fibers. If having saturated synaptic sites is critical, retinotopic refinement should be impeded or prevented.

Refinement was monitored as in previous studies (Olson and Meyer, 1991a) by labeling optic fibers from a small number of neighboring ganglion cells with a $2 \mathrm{nl}$ injection of WGA conjugated to HRP (WGA-HRP) and visualizing the anterograde transport of the HRP with tetramethyl benzidine histochemistry. This method, referred to as "spol mapping," was done at various times between 30 and $138 \mathrm{~d}$ after deflection. In some fish, activity was blocked by intraocular injections of TTX to distinguish between activity-sensitive and -insensitive processes.

Contrary to what might be expected from some competition models, we found the extent of activity-dependent retinotopic refinement in this low-density projection to be almost the same as after simple optic nerve crush when a full complement of optic fibers regenerates back into the optic tectum. We also found there was considerable refinement under activity blockade, although the fibers remained more dispersed than after simple optic nerve crush.

\section{Materials and Methods}

Animals. Common goldfish, Carassius auratus, $5-7 \mathrm{~cm}$ in body length were maintained in standard glass aquaria under diurnal illumination, $12 \mathrm{hr}$ light: $12 \mathrm{hr}$ dark, at about $19^{\circ} \mathrm{C}$.

Surgery. The fish were anesthetized with tricaine methanesulfonate (Finquel), held in a moist wrapping, and observed under a stereomicroscope. The surgical procedures have been described in detail previously (Meyer, 1978, 1984).

For the fiber deflection, optic fibers from the medial brachia supplying the posterior quadrant were dissected from the optic tectum as a long anteroposterior strip along the medial margin of the tectum. The anterior end was left intact so as to preserve the integrity of the optic fiber path from the retina. This strip was then lifted over the midline and inserted into a small incision in the anterior medial end of the opposite (host) tectum. At the same time the host tectum was denervated of its optic fibers by enucleation of the eye normally innervating it. This procedure produces retinal innervation that is restricted to somewhat less than the ventral nasal quadrant of retina (Meyer, 1984).

Injections. Intraocular injections of tetrodotoxin (TTX) were made as previously described (Meyer, 1982). A glass pipette was inserted into the posterior chamber made through a hole slightly posterior to the limbus. Injections were started $5 \mathrm{~d}$ after the optic fiber deflection and given every $42-48 \mathrm{hr}$. Fish were injected with $0.05 \mu \mathrm{l}$ of $1.2 \mathrm{~mm}$ solution of tetrodotoxin in the $0.05 \mathrm{~m}$ sodium citrate buffer. Comparison animals, designated here as "NO-TTX," were similarly injected but with 0.05 $\mu$ of $0.05 \mathrm{M}$ sodium citrate buffer. Previous studies with goldfish have documented the amount of effective blockade, both directly with electrophysiology (Meyer, 1982; Schmidt and Fdwards, 1983) and indirectly by effects on the projection (Meyer, 1982, 1983b; Olson and Meyer, 1991a). To be sure activity blockade was complete, we used four times 
Table 1. Dimensions and area of tectal label

\begin{tabular}{|c|c|c|c|c|c|c|c|}
\hline & \multirow[b]{2}{*}{$N$} & \multicolumn{2}{|c|}{$30-40 \mathrm{~d}$} & \multicolumn{2}{|c|}{$60-70 \mathrm{~d}$} & \multicolumn{2}{|c|}{$90+d$} \\
\hline & & ML & AP & $\mathrm{ML}$ & AP & ML & AP \\
\hline $\begin{array}{l}\text { Normal } \\
\text { (SE) }\end{array}$ & 4 & & & & & $\begin{array}{c}260 \\
(7)\end{array}$ & $\begin{array}{l}260 \\
(21)\end{array}$ \\
\hline Area & & & & & & \multicolumn{2}{|c|}{53} \\
\hline $\begin{array}{l}\text { Deflection, No-TTX } \\
\text { (SE) }\end{array}$ & 17 & $\begin{array}{c}700 \\
(104)\end{array}$ & $\begin{array}{c}650 \\
(100)\end{array}$ & $\begin{array}{l}525 \\
(60)\end{array}$ & $\begin{array}{c}500 \\
(126)\end{array}$ & $\begin{array}{l}290 \\
(23)\end{array}$ & $\begin{array}{l}300 \\
(41)\end{array}$ \\
\hline Area & & \multicolumn{2}{|c|}{357} & \multicolumn{2}{|c|}{206} & \multicolumn{2}{|c|}{68} \\
\hline $\begin{array}{l}\text { Deflection, TTX } \\
\text { (SE) }\end{array}$ & 9 & $\begin{array}{l}1150 \\
(176)\end{array}$ & $\begin{array}{l}1650 \\
(212)\end{array}$ & $\begin{array}{c}950 \\
(141)\end{array}$ & $\begin{array}{l}1175 \\
(106)\end{array}$ & $\begin{array}{l}675 \\
(56)\end{array}$ & $\begin{array}{l}850 \\
(43)\end{array}$ \\
\hline Area & & \multicolumn{2}{|c|}{1490} & \multicolumn{2}{|c|}{877} & \multicolumn{2}{|c|}{451} \\
\hline $\begin{array}{l}\text { Nerve crush, }{ }^{a} \text { No-TTX } \\
\text { (SE) }\end{array}$ & 15 & $\begin{array}{l}560 \\
(28)\end{array}$ & $\begin{array}{l}530 \\
(67)\end{array}$ & $\begin{array}{l}280 \\
(24)\end{array}$ & $\begin{array}{l}250 \\
(15)\end{array}$ & $\begin{array}{l}240 \\
(20)\end{array}$ & $\begin{array}{l}250 \\
(14)\end{array}$ \\
\hline Area & & \multicolumn{2}{|c|}{233} & \multicolumn{2}{|c|}{55} & \multicolumn{2}{|c|}{47} \\
\hline $\begin{array}{l}\text { Nerve crush, }{ }^{a} \text { TTX } \\
\text { (SE) }\end{array}$ & & $\begin{array}{l}834 \\
(54)\end{array}$ & $\begin{array}{l}650 \\
(12)\end{array}$ & $\begin{array}{l}675 \\
(54)\end{array}$ & $\begin{array}{l}530 \\
(32)\end{array}$ & $\begin{array}{l}550 \\
(64)\end{array}$ & $\begin{array}{l}390 \\
(18)\end{array}$ \\
\hline Area & 15 & \multicolumn{2}{|c|}{426} & \multicolumn{2}{|c|}{281} & \multicolumn{2}{|c|}{168} \\
\hline
\end{tabular}

ML, Medial-lateral dimension; AP, anterior-posterior dimension. Dimensions and SE are in micrometers. Area is $\times 10^{3}$ $\mu \mathrm{m}^{2} . N$ is the number of goldfish per experimental condition.

"Data reproduced from Table 1 of Olson and Meyer (1991a), where optic fiber number was normal.

the dosage and a more frequent injection schedule than was previously found to be effective (Meyer, 1982).

Anterograde labeling and histochemistry. Retinal labeling was done with a positive displacement liquid-filled microinjection system that was mounted on a micromanipulator. The tip consisted of a micropipette with a tip diameter of $30 \mu \mathrm{m}$ (Meyer et al., 1985). A small patch of sclera, $<0.5 \mu \mathrm{m}$ across, was removed to expose the underlying choroid through which the micropipette was inserted. At a depth of $350 \mu \mathrm{m}$ and $450 \mu \mathrm{m}, 1 \mathrm{nl}$ of $2 \%$ wheat germ agglutinin conjugated to horseradish peroxidase (WGA-HRP) was injected into the peripheral ventral nasal retina corresponding to the deflected optic fibers. A total of 43 experimental fish were injected with WGA-HRP; however, not all injections produced tectal label, so only data from 26 fish with label are described (Table 1).

At about $18 \mathrm{hr}$ after the WGA-HRP injection, the fish were anesthetized with Finquel and perfused through the heart with $5-10 \mathrm{ml}$ of teleost Ringer's containing Finquel followed by $10-15 \mathrm{ml}$ of a solution of $2 \%$ glutaraldehyde and $1 \%$ paraformaldehyde. The brain was removed and postfixed in the latter for $1 \mathrm{hr}$ and then placed in a 30\% sucrose buffer solution until equilibration. The brain was mounted in Tissue-Tek II O.C.T. compound, frozen, and serially sectioned at $50 \mu \mathrm{m}$ through the entire tectum. The sections were collected in baskets and reacted with the tetramethyl benzidine method of Mesulam (1978). The sections were then mounted on slides, cleared, and coverslipped without counterstaining.

Morphometry. In some animals, particularly the TTX-treated ones, label was widely dispersed and very light at its edges. This light label could not be reliably measured with the scanning spot densitometry used in our previous study (Meyer et al., 1985), so the distribution was estimated by measuring the borders of detectable label. The distribution of SFGS label in the medial-lateral dimension was done with a calibrated eyepiece reticule under high magnification to an estimated accuracy of 10-20 $\mu \mathrm{m}$. This measurement reflected the maximum mediallateral dimension over which label was detected above background levels. The anterior-posterior SFGS dimension was measured by counting the number of $50 \mu \mathrm{m}$ sections that contained label. This was estimated to within a half section $(25 \mu \mathrm{m})$ by focusing through the section under high power. The area of the label was calculated by using the standard formula for the area of an ellipse, $\pi a b(a, b=$ semiaxis of the ML and AP dimensions, respectively).

In animals where label was widely dispersed, there was typically a large flanking region of very light label of roughly constant density, which may represent label from fibers of passage. At low power, this flanking material was so sparse as not to be apparent. This flanking label was excluded from the measure. In this case the edge of the label was arbitrarily defined as the point where density fell to this "background" of constant density. The exclusion of the flanking regions did not affect any of the conclusions, which were based on large qualitative differences.

\section{Results}

In a previous study on fish with simple optic nerve crush (Olson and Meyer, 1991a), we distinguish three periods of regeneration for the purpose of presenting our findings: an early period between 30 and $40 \mathrm{~d}$ of regeneration when rough retinotopy has been established and the normal number of synapses has been restored, an intermediate period between 60 and $70 \mathrm{~d}$ when much of the activity-dependent ordering has been completed, and a late period after $90 \mathrm{~d}$ when retinotopic refinement is essentially complete. For purposes of comparison, we have retained this nomenclature and present data from this previous study, referred to as "nerve crush," in Table 1 along with the present results, referred to as "deflection."

Table 1 lists the AP and ML dimensions and the area of the tectal label measured at the three separate time periods. The data from Table 1 were used to create two additional tables used to evaluate refinement: Table 2, "absolute refinement," and Table 3, "relative refinement." Absolute refinement is defined as the area of tectal label observed at one of the three time periods in the experimental condition, "deflection" (low fiber density), divided by the area of tectal label observed at the same time period in the standard condition, "nerve crush" (normal fiber density). Absolute refinement is a measure of the effect of fiber density on the normal progress of refinement. A value greater than 1 means that fibers project to a larger area of tectum in low fiber density animals compared to animals with normal fiber density; that is, there was less refinement than after simple optic nerve crush. Relative refinement is defined as the area of tectal label observed at one of the time periods for each experimental condition divided by its own area at $30 \mathrm{~d}$. Relative refinement is a measure of the amount of change (refinement) 
Table 2. Effect of density on absolute refinement

\begin{tabular}{|c|c|c|c|}
\hline & $30-40 d$ & $60-70 \mathrm{~d}$ & $90+d$ \\
\hline$\frac{\text { No-TTX deflection }}{\text { No-TTX nerve crush }}$ & 1.5 & 3.7 & 1.4 \\
\hline$\frac{\text { TTX deflection }}{\text { TTX nerve crush }}$ & 3.5 & 3.1 & 2.7 \\
\hline
\end{tabular}

Area of label measured at each time period is expressed as a ratio between deflection and optic nerve crush: (area of tectal label in deflected projection) $\div$ (area of tectal label in simple optic nerve crush). Values for these areas are given in Table 1 .

observed within each group of animals. Smaller numbers mean more refinement, that is, greater condensation of tectal label relative to that seen at $30 \mathrm{~d}$.

\section{Label in a normal retinotectal projection}

When a spot injection of WGA-HRP is made into the retina of a normal goldfish, a small, well-defined patch of product is found in the retinotopically appropriate location of the optic tectum (Fig. 1 $A, B$; Table 1). The central portion of the patch contains dense label that falls off abruptly at its periphery, resulting in a sharp edge (Fig. $1 B$ ). The product filled the SFGS, the main optic terminal layer, and the S-lamina, a narrow optic layer just above the SFGS. There was very light or undetectable label in the other minor optic layers and no label was observed in nonoptic layers. This patch of label from "spot mapping" has been described in detail earlier (Meyer et al., 1985). The dimensions of this patch of product are highly uniform from fish to fish, attesting to the reproducibility of the spot mapping technique (Table 1).

\section{Label in deflected projection with normal activity}

After the optic fiber deflection and enucleation, the fish were divided into two separate groups. One group received intraocular injections of citrate buffer every $42-48 \mathrm{hr}$, starting $5 \mathrm{~d}$ after the surgery. This injection schedule was the same as for the activity-blocked TTX animals. The other group received no intraocular injections. The results from these two groups were not detectably different, as expected from a similar comparison in our previous study on fish with optic nerve crush (Olson and Meyer, 1991a). For purposes of simplification, the results from these two groups are combined and presented together here.

At $30 \mathrm{~d}$, the tectal label from a retinal spot injection of WGAHRP was widely dispersed (Fig. $1 C$, Table 1). In the AP dimension the product began approximately $500 \mu \mathrm{m}$ from the anterior end of the tectum and in the ML dimension product extended to its medial edge (Fig. 2). The product was concentrated in a roughly circular zone in the appropriate tectal quadrant, and there were no sharp boundaries to the label. The tectal label in the deflected projection was initially 50\% larger than after simple optic nerve crush, as indicated by the absolute refinement measure of lable 2.

At $60 \mathrm{~d}$, the product was much more condensed (Fig. $1 D$, Table 1), as indicated by the rclative refinement value of Table 3 being less than 1 . The labeled area had retracted to almost half its earlier size in roughly the retinotopically appropriate tectal region and formed distinct patches that were more dense than the label at $30 \mathrm{~d}$. These patches no longer extended to the medial edge of the tectum and their edges were still somewhat diffuse. As shown by the absolute refinement measure (Table
Table 3. Effect of density on relative refinement

\begin{tabular}{llll} 
& $30-40 \mathrm{~d}$ & $60-70 \mathrm{~d}$ & $90+\mathrm{d}$ \\
\hline No-TTX deflection & 1 & 0.58 & 0.19 \\
No-TTX nerve crush & 1 & 0.24 & 0.20 \\
TTX deflection & 1 & 0.59 & 0.30 \\
TTX nerve crush & 1 & 0.66 & 0.39
\end{tabular}

Area of label measured at each time period for each experimental condition is expressed as a ratio to its area at $30 \mathrm{~d}$ : (area of tectal label at 30,60 , or $90 \mathrm{~d}$ ) $\div$ (area of tectal label at $30 \mathrm{~d}$ ). Values for these areas are given in Table 1

2), these patches were nearly four times larger than in animals with simple optic nerve crush. This size difference was partly a result of slower refinement in the deflected group, as indicated by the relative refinement measure being half as great when compared to the ncrve crush group (Table 3). Also, labcl in this deflected projection did not form multiple patches as observed previously with simple optic nerve crush (Meyer et al., 1985; Olson and Meyer, 1991a).

At $90 \mathrm{~d}$, the patches of product were more condensed and their edges were more defined than at $60 \mathrm{~d}$ (Fig. 1E, Table 1). The product had condensed to one-fifth the area found at $30 \mathrm{~d}$, as shown by the relative refinement measure (Table 3 ). These patches were now only slightly larger than the patches of product observed in normal goldfish or in regeneration after simple optic nerve crush (Tables 1,2 ), although their edges were not quite as sharp. The significant condensation that occurred by this time was associated with a movement of the tectal label posteriorly, which now began approximately $650 \mu \mathrm{m}$ from the anterior end of the tectum (Fig. 2). As shown by the absolute refinement measure (Table 2), label in the deflected projection was now close to normal, only $40 \%$ larger than after simple optic nerve crush at this same time.

\section{Label in deflected projection with TTX activity blockade}

Surgical deflections and enucleations were the same as above and intraocular injections of TTX were begun $5 \mathrm{~d}$ after the surgery and repeated every $42-48 \mathrm{hr}$. After $30 \mathrm{~d}$ of regeneration, the label from a retinal spot injection of WGA-HRP was widely dispersed in the tectum, much more so than in fish with normal activity (Fig. $1 F$, Table 1 ). The label began approximately 400 $\mu \mathrm{m}$ from the anterior end of the tectum and extended to its medial edge (Fig. 3). The product was nearly uniform throughout the labeled area. It was in the appropriate tectal quadrant and tapered off gradually giving indistinct boundaries. The tectal label in the deflected projection was initially $350 \%$ larger than after simple optic nerve crush, as shown by the absolute refinement measure of Table 2.

After $60 \mathrm{~d}$, the product was more concentrated in the appropriate tectal quadrant, though the label still extended to the medial edge of the tectum (Fig. $1 G$, Table 1). The boundaries were slightly more defined than at $30 \mathrm{~d}$. As shown by the relative refinement measure (Table 3), label contracted to about half its area observed at $30 \mathrm{~d}$. Label was still more spread out compared to the nerve crush group, but as indicated by the absolute refinement measure (Table 2), the difference between these two groups was comparable to that seen at $30 \mathrm{~d}$. The size difference of the labeled area at this time was not due to slower refinement in the deflected group because the relative refinement measure was about the same as the nerve crush group (Table 3 ).

At $90 \mathrm{~d}$, the projection had condensed to $30 \%$ of the area 

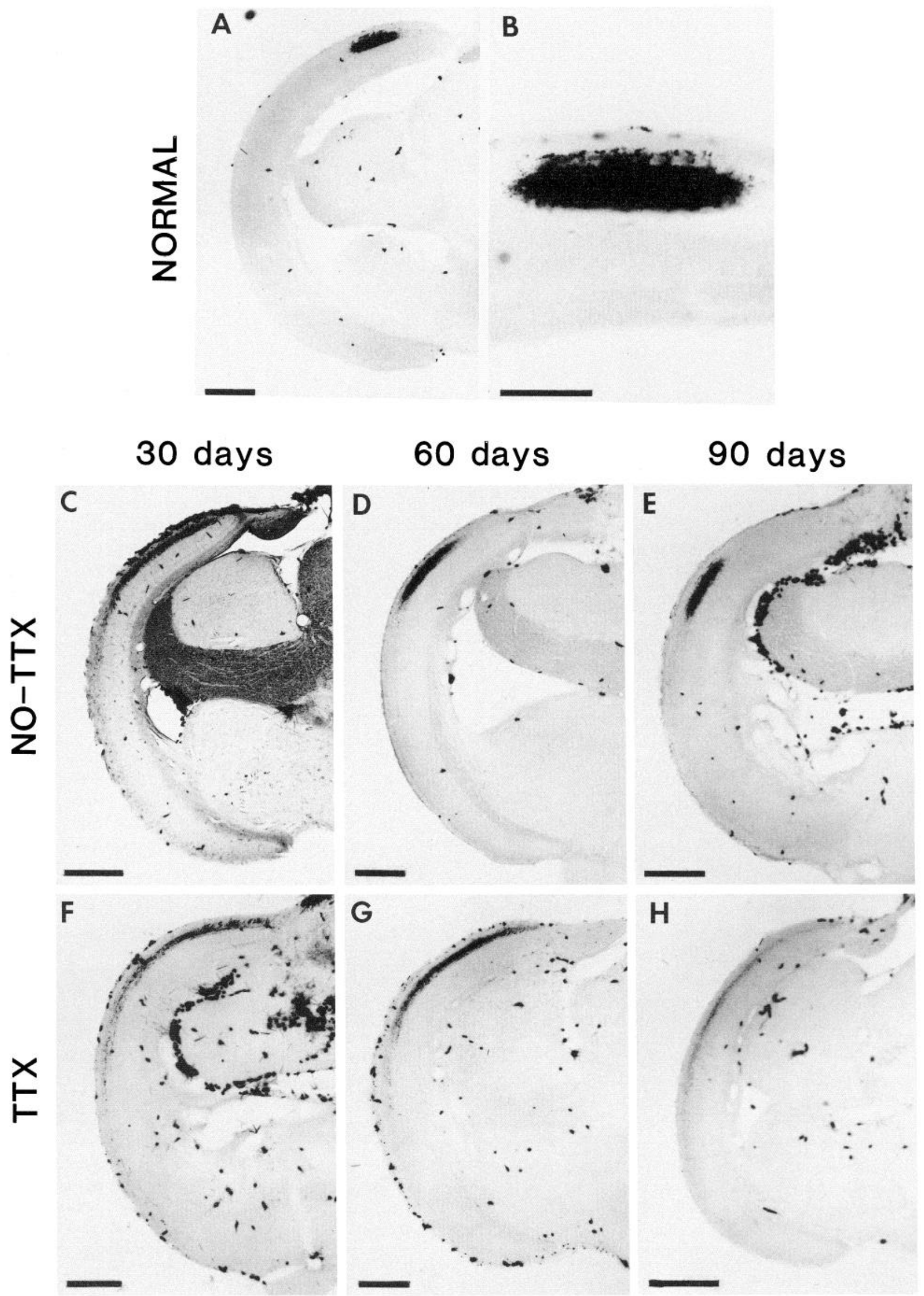
occupied at $30 \mathrm{~d}$ (Table 3 ). The product was in the appropriate tectal quadrant, and had become more dense. The boundaries were still not well defined (Fig. $1 H$ ). Anteriorly, the product began approximately $400 \mu \mathrm{m}$ from the front of the tectum and no longer extended to its medial edge (Fig. 3). The label never segregated into multiple patches as observed with activity. The relative amount that label had condensed from $30 \mathrm{~d}$ was as much as in animals with nerve crush, as indicated by the relative refinement measures of Table 3 . However, the actual size of the area occupied by the tecta label was still nearly three times larger than with nerve crush, as indicated by the absolute refinement measure of Table 2 .

\section{Discussion}

The main finding was that there was nearly normal activitydependent retinotopic refinement in a low-density projection in the presence of unfilled synaptic sites. Neighboring optic fibers from a small area of retina were initially widely dispersed in the tectum, and with time condensed to a size only moderately larger than that previously observed when the normal number of optic fibers were present (Meyer et al., 1985; Olson and Meyer, 1991a). We suggest that competition for fixed numbers of synaptic sites may not be essential for activity-dependent refinement and that this may instead be mediated by a cooperative process. In addition, activity-independent refinement (refinement under TTX blockade) was also observed but it was partially inhibited by the low density of optic fibers. This suggests that competition may he more important for activity-insensitive processes than for activity-dependent processes. These results will be discussed in terms of the following four topics: activityindependent refinement, activity-dependent refinement, refined retinotopy in an expanded projection, and implications for competitive versus cooperative processes.

\section{Activity-independent retinotopic refinement}

Under continuous TTX blockade, a progressive refinement took place over several months reminiscent of that previously seen under TTX when the optic nerve was simply crushed (Olson and Meyer, 1991a). Substantial reduction in the size of tectal label was observed at $60 \mathrm{~d}$ and this further decreased by $90 \mathrm{~d}$ to become $30 \%$ of the area occupied at $30 \mathrm{~d}$. However, it remained 2.7 times larger than that obscrved in previous TTX studies in which the number of fibers was normal. On the one hand, this finding means that an activity-independent refinement can take place in the presence of "vacant" synaptic sites. On the other hand, this result indicates that activity-independent refinement is partially inhibited by the low density of fibers.

The observed refinement could be explained in terms of chemoaffinity-directed growth. Several studies have shown that optic fibers silenced with TTX can form a roughly ordered retinotopic projection (Harris, 1980; Meyer, 1983b; Schmidt and Edwards, 1983; Olson and Meyer, 1991a). Directed growth has also been demonstrated for a low-density projection in which fibers were required to grow past unfilled synaptic sites. Using the deflection procedure similar to that used in the present study, it was shown that when a subset of optic fibers was introduced into the wrong half of a denervated tectum, they grew toward their appropriate half just as well under TTX blockade as with normal activity (Meyer, 1987). While these previous studies did not show the progressive improvement in retinotopic order (refinement) as demonstrable with the spot mapping method used here, it seems reasonable to interpret this refinement as a progressive growth toward their appropriate tectal region, which is presumably based on chemoaffinity cueing and does not require activity (Sperry, 1963).

The more curious finding is that activity-independent refinement was partially inhibited; that is, labeled fibers were more dispersed in this low-density projection than when the density was normal. This inhibition was not simply due to a disruptive effect of the deflection surgery. It was previously shown that when similarly deflected fibers were introduced into the host tectum at the same time that host optic fibers were made to reinnervate host tectum, they eventually occupied a normalsized region of tectum even under TTX blockade (Meyer, 1982). Also, the present finding that deflected fibers without TTX treatment underwent nearly normal refinement similarly argues against mechanical disruption. Rather, it appears that the partial inhibition of activity-independent refinement is due to the low density of fibers. This, in turn, could be taken to mean that competition somehow regulates the activity-independent processes responsible for generating gross retinotopy.

There is longstanding evidence consistent with the idea that competition regulates gross retinotopy. When half of retina is removed, fibers from the remaining retina can expand to fill available tectal space (Schmidt et al., 1978; Udin and Gaze, 1983). Retinotopic expansion also results when a fraction of optic fibers are deflected into denervated tectum (Meyer, 1978) in the manner of the present study. Conversely, when half of tectum is removed, optic fibers will form a compressed projection onto the tectal remnant (Gaze and Sharma, 1970; Yoon, 1971; Meyer, 1977). More recently, both expansion and compression have been shown to take place under TTX blockade (Meyer and Wolcott, 1987) and thus can be directly attributed to activity-independent mechanisms.

The conclusion that this evidence suggests is that competition for available tectal spacc is responsible for controlling largescale retinotopy through an activity-independent mechanism. If "tectal space" is taken to mean optic synaptic sites, which is the only known limited resource in tectum, then this competition could be for synaptic sites. Such a competition would normally ensure that all optic fibers make synapses and all available sites are filled.

\section{Activity-dependent retinotopic refinement}

Surprisingly, when activity was permitted, the degree of refinement produced in this low-density projection was nearly normal. By $90+d$, the area of tectum occupied by optic fibers that were labeled by the small retinal spot injection was only slightly larger

\footnotetext{
Figure 1. Representative examples of tectal spot label in normal fish and in fish at various times after deflection with and without TTX blockade. Sections are of left tectum in frontal orientation with dorsal at top and medial to the right. A single $2 \mathrm{nl}$ spot injection of $2 \%$ WGA-HRP was made into the nasal-ventral retina. $A$, Frontal section through tectum of normal (untreated) goldfish. $B$, High nerve deflection into denervated tectum at 30,60 , and $90 \mathrm{~d}$. Sections were selected where the product was most widely distributed across the mediolateral axis. C-E, These $N O-T T X$ fish received $0.05 \mu \mathrm{l}$ of $0.05 \mathrm{M}$ sodium citrate buffer every $42-48 \mathrm{hr}$ beginning $5 \mathrm{~d}$ after deflection. $F-H$, The TTX-treated fish received $0.05 \mu \mathrm{l}$ of 1.2 mM tetrodotoxin in citrate buffer every $42-48 \mathrm{hr}$ beginning $5 \mathrm{~d}$ after deflection. Scale bars: $A$ and $C-H, 250 \mu \mathrm{m} ; B, 100 \mu \mathrm{m}$.
} 


\section{0 days}
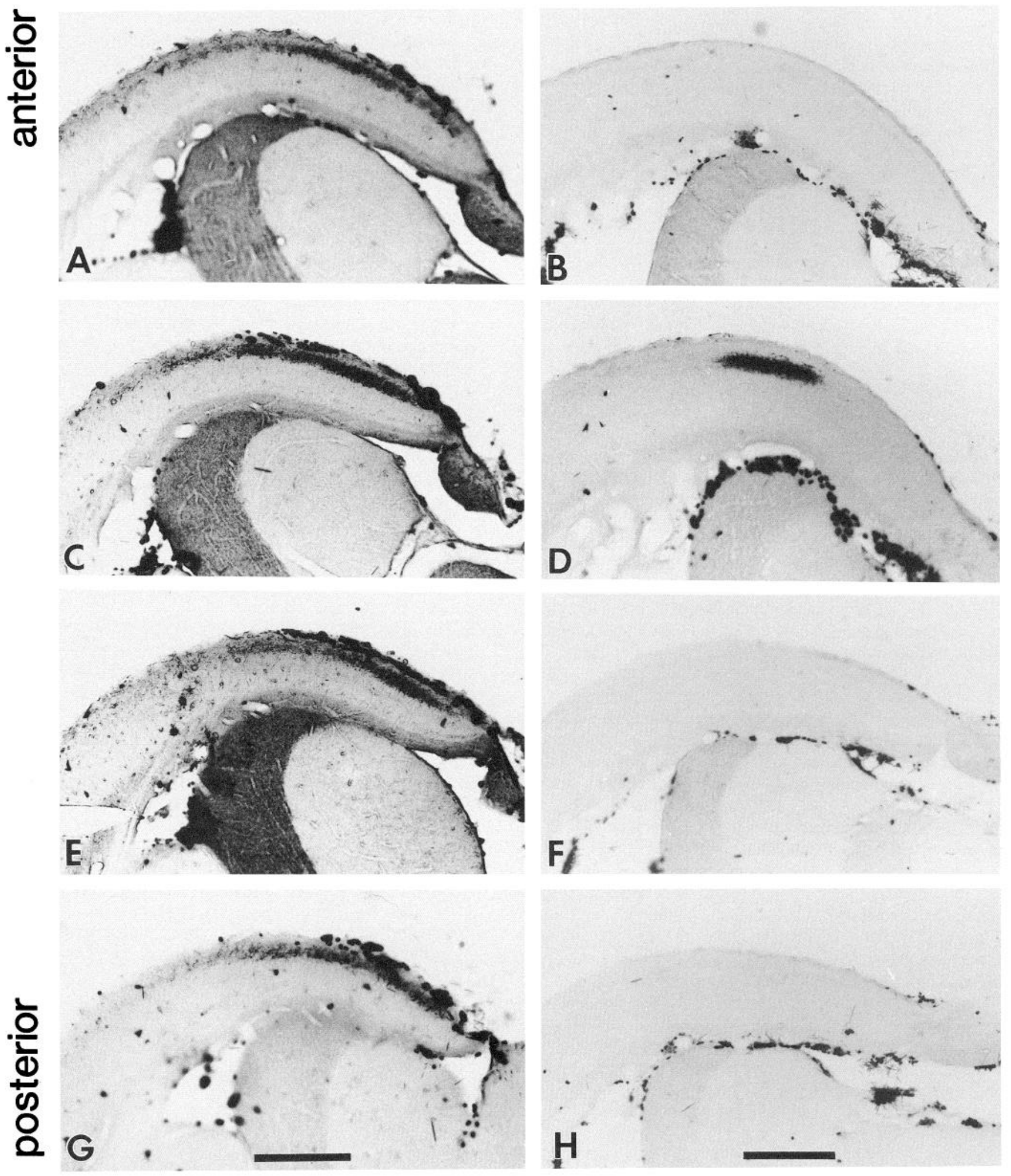

Figure 2. An anterior-posterior series of frontal sections taken through dorsal tectum from a NO-TTX fish at 30 and $90 \mathrm{~d}$ after deflection. $A$, $C$, $E$,, and $G$, Fish at $30 \mathrm{~d}$. $B, D, F$, and $H$, Fish at $90 \mathrm{~d}$. Anterior-posterior positions are as follows: $A$ and $B, 600 \mu \mathrm{m}$ from the anterior end; $C$ and $D, 800 \mu \mathrm{m}$ from the anterior end; $E$ and $F, 1000 \mu \mathrm{m}$ from the anterior end; $G$ and $H, 1200 \mu \mathrm{m}$ from the anterior end. Scale bars, $250 \mu \mathrm{m}$. 


\section{0 days}
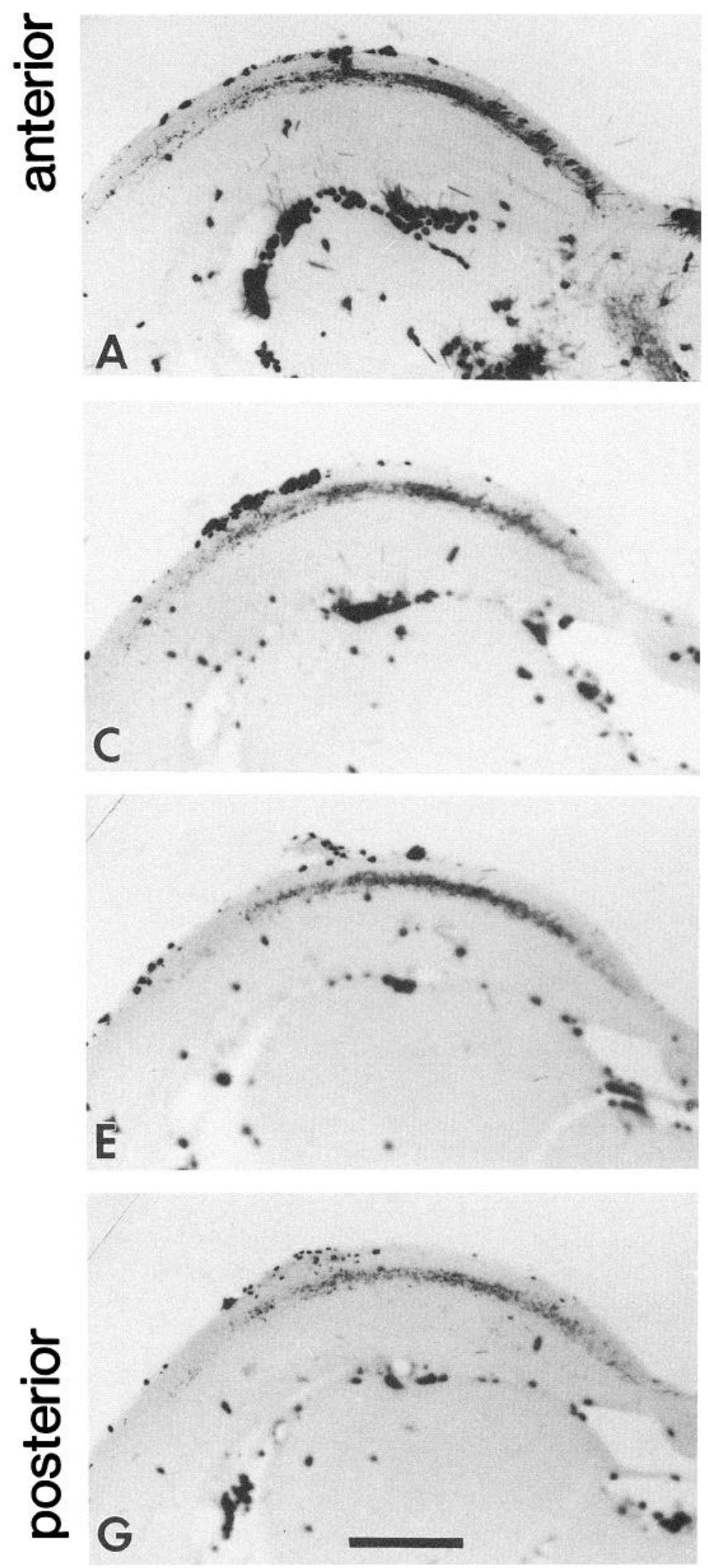

\section{0 days}

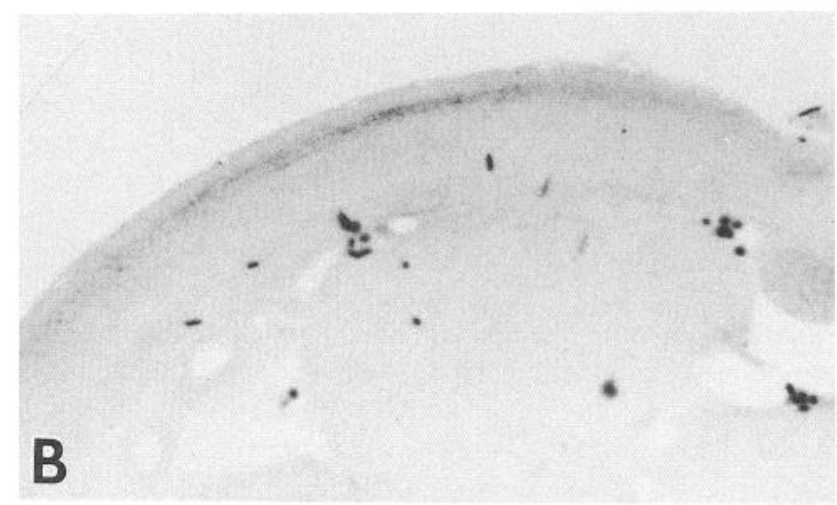

D
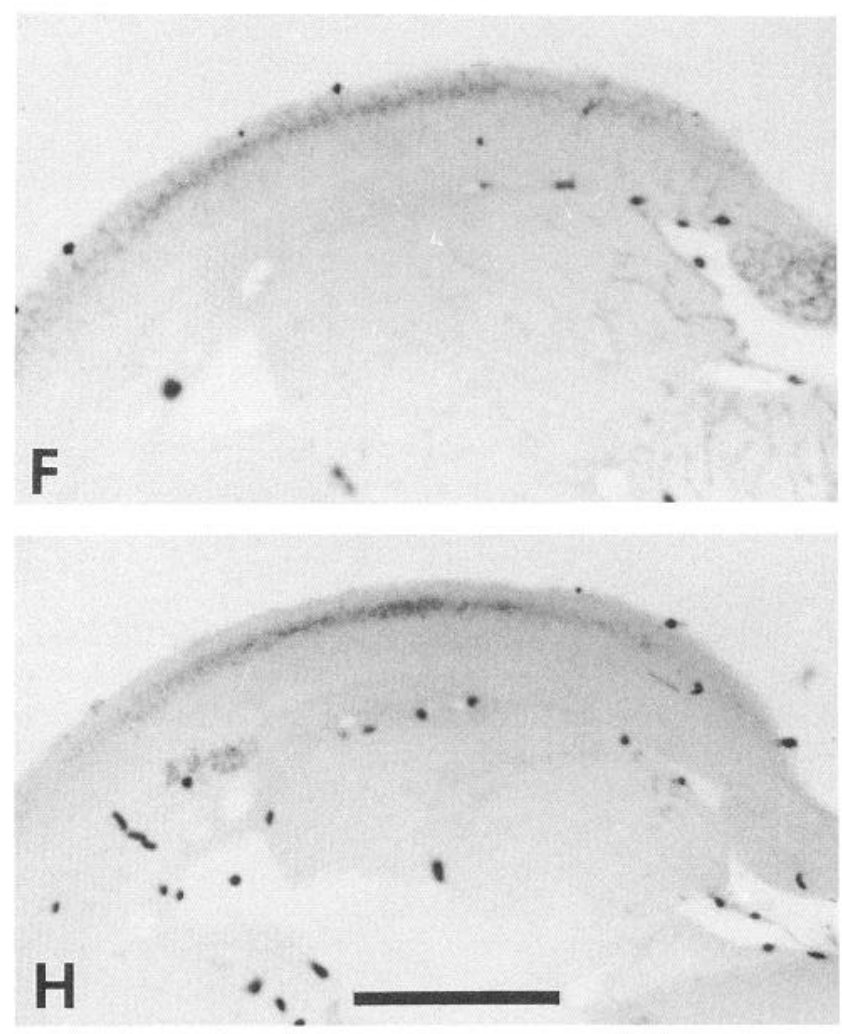

Figure 3. An anterior-posterior series of frontal sections taken through dorsal tectum from a TTX-treated fish at 30 and $90 \mathrm{~d}$ after deflection. $A$, $C, E$, and $G$, Fish at 30 d. $B, D, F$, and $H$, Fish at $90 \mathrm{~d}$. Anterior-posterior positions are as follows: $A$ and $B, 600 \mu \mathrm{m}$ from the anterior end; $C$ and $D, 800 \mu \mathrm{m}$ from the anterior end; $E$ and $F, 1000 \mu \mathrm{m}$ from the anterior end; $G$ and $H, 1200 \mu \mathrm{m}$ from the anterior end. Scale bars, $250 \mu \mathrm{m}$. 
$(1.4 \times)$ than that observed when normal numbers of fibers were present. This was all the more remarkable considering the much greater contribution activity made to refining this low-density projection. This contribution can be estimated by comparing the area occupied by active fibers with that of fibers silenced by TTX. In the low-density projection, silenced fibers were spread over nearly seven times more tectal area at $90+\mathrm{d}$. This contrasts to that of a normal-density projection where silenced fibers occupied only 3.5 times more area than active fibers at $90+\mathrm{d}$. In other words, activity contributed about twice as much to refinement in the low-density projection. The reasons for this greater contribution from activity may be that fibers tend to expand across tectum in the low-density projection as a result of activity-independent processes (see above) and labeled fibers may have been more dispersed when they invaded tectum. Activity-dependent refinement would need to overcome both of these counteracting effects.

This finding means that optic fibers can use correlated activity to converge onto a small region of tectum even when there are many vacant optic synaptic sites. Under the conditions of this experiment, there were less than $40 \%$ the normal number of optic synapses (Hayes and Meyer, 1988b), and this is probably a substantial overestimate since the counts were obtained after refinement and were taken in the region of highest afferent density. This reduction in optic synapses is not accompanied by an increase in the number of nonoptic synapses in the optic innervation layer (SFGS), which remain constant in both the lowdensity projection and in tecta denervated of all optic fibers (Murray and Edwards, 1982; Hayes and Meyer, 1988b). Since the maximum (normal) number of optic synaptic sites is dictated by tectal cells and cannot be increased by increasing the number of optic fibers above normal (Murray et al., 1982; Hayes and Meyer, 1988a), this implies that at least $60 \%$ of potential optic synaptic sites are unfilled in the low-density projection.

At first sight, the finding that nearly normal activity-dependent refinement eventually occurred when synaptic numbers were much lower than normal might seem contrary to the presumption that activity mediates refinement via synaptic connections. However, a closer look at the data indicates otherwise. Refinement was much slower in the low-density projection. Spot labeled fibers were more than three times as spread out at $60 \mathrm{~d}$ than at $90 \mathrm{~d}$. In contrast, when fiber density is normal, refinement is largely completed by $60 \mathrm{~d}$ improving by $15 \%$ at $90 \mathrm{~d}$. Since at $30 \mathrm{~d}$ there was only a modest difference in retinotopic order between low- and normal-density projections, the lag in refinement between 30 and $90 \mathrm{~d}$ is likely due to decreased synaptic density rather than initial disorganization. We suggest, therefore, that low synaptic density slows the rate of activitydependent refinement while not greatly affecting the end point. When optic fibers form fewer synaptic connections onto tectal cells, it is not unreasonable to think they might be less efficient at driving tectal cells and that this, in turn, could delay the efficiency or onset of activity-dependent refinement.

Another observation that points to synaptic function is the surprisingly large contribution that activity apparently made by $30 \mathrm{~d}$. With activity, spot-labeled fibers occupied one-fourth the area of tectum than under TTX blockade at this early time. This suggests a significant role for activity beginning with the initial entry of optic fibers into the tectum, much sooner than has been generally appreciated. Whether this early effect of activity is actually attributable to synaptic function or to some nonsynaptic effect of impulse blockade at early stages of regeneration (Ed- wards and Grafstein, 1984; Antonian et al., 1987) will need further testing.

\section{Topographic implications of refinement in an expanded projection}

There are two seemingly contradictory aspects of the topography of the final projection formed by these deflected fibers that warrant brief mention. On the onc hand, ncighboring retinal ganglion cells converged into an area of tectum that was roughly normal in size. On the other hand, the fibers as a group expanded into over two to three times the area they occupy in a normal projection (Meyer, 1978). A similar dichotomy has recently been found in a compressed projection in which fibers from the entire eye were made to innervate a surgically formed anterior half tectum (Olson and Meyer, 1991b). In this case, the projection, as a whole, was retinotopically squeezed into half its normal area of tectum while the area of tectum to which neighboring ganglion cells projected, as measured by retinal spot injections, was essentially normal.

We suggest that the resolution of these dichotomous features of the retinotopy lies in the fact two different aspects of topography are being measured. Expansion and compression measure the large-scale distribution of optic fibers. The spot mapping method measures local order. What these experiments show is that the relationship between these two aspects of retinotopy are not as simple as first meets the eye. One might naively imagine that if one labeled two neighboring clusters of retinal ganglion cells, one might see two contiguous, nonoverlapping spots of label in a normal tectum. The available evidence, however, suggests that these two projection zones must partially overlap in a normal tectum (Wang and Meyer, 1991). When the map is expanded, the overlap can decrease without creating denervated regions of tectum. When the map is compressed, the overlap can increase while preserving retinotopy. If the extent of overlap is sufficiently great, the size of the spot label in tectum will show relatively small changes during expansion and compression.

To illustrate this, imagine that at its edges a retinal injection labeled two optic arbors that were each $200 \mu \mathrm{m}$ in diameter and that their centers were separated by $50 \mu \mathrm{m}$. Together they would subtend a $250 \mu \mathrm{m}$ length of tectum. If expansion doubled the distance between the centers of these arbors to $100 \mu \mathrm{m}$, then the length of tectum subtended would increase only to $300 \mu \mathrm{m}$. This would be only a $20 \%$ increase, which is about what we actually observed. The percentage change in compression would be even smaller. We will discuss this issue at length elsewhere in the context of compression (M. D. Olson and R. L. Meyer, unpublished observations).

\section{Neuronal activity may mediate a cooperative process in retinotopic refinement}

The main finding here, that activity-dependent refinement was nearly normal in this low-density projection, demonstrates that salurated synaptic sites are not a necessary condition for activity-mediated refinement. This result does not provide support for a role for synaptic competition in this process. On the contrary, the fact that fibers from neighboring retinal ganglion actively converged into a small area of tectum when large numbers of "vacant" alternative synaptic sites were present leads us to suggest that activity may mediate a process that is cooperative instead of competitive.

To clarify what "cooperative" might mean, it is helpful to 
contrast two extreme models, one competitive and the other cooperative. For both models, we will presume, as is the case for goldfish tectum, that the maximum number of synaptic sites is limited by the target cell, and that, under normal conditions, fibers have the inherent capacity to make more synaptic connections than are available. For the competition model, two further assumptions are made: (1) an activity related negative feedback signal that destabilizes synapses that would otherwise automatically persist and (2) the competitive replacement of fibers at these destabilized synapses by neighboring fibers. The rule for synapse destabilization (negative feedback) would be that postulated by Stent's (1973) extension of the Hebbian synapse (Hebb, 1949), in which asynchronous pre-and postsynaptic activity produces destabilization of the active synapse. Because there was an excess of afferent fibers relative to synaptic sites, fibers at destabilized synapses would be replaced by other fibers. Those having activity synchronous with the postsynaptic cell would be spared the noxious effects of the negative feedback signal and would persist. Under the low-density conditions of the present experiment, the competitive pressure should be absent or greatly reduced because the large numbers of available synaptic sites would permit fibers to make as many synaptic connections as they are able. As a result, there would be nothing to induce fibers to displace existing synaptic connections even when destabilized, and consequently, synaptic connections would persist, thereby impeding synaptic rearrangement.

In contrast, a cooperative model could be thought of as having these alternative characteristics: (1) synaptic connections that are inherently unstable, having limited life-span, unless stabilized, and (2) a stabilizing signal (positive feedback) that is activated by correlated activity and is necessary for long-term survival of synapses. The rule for stabilization could still be Hebbian; that is, synapses of fibers coactive with postsynaptic cells would be preferentially stabilized. Because synaptic connections are normally short-lived, it would only be necessary to stabilize preferentially those synapses that show correlated pre- and postsynaptic activity. When the density of synapses is low, activity-dependent rearrangement could still occur because of the inherent instability of synaptic connections. Rearrangement would proceed until a stabilization signal is activated although final stabilization may take longer when synapses are reduced (as was observed). In effect, the positive fecdback signal actively promotes the trial-and-error convergence of coactive fibers without the necessity of competition.

Another possible example of cooperativity in topographic refinement may be the formation of binocular maps in Xenopus. In this system, there is an ipsilateral projection relayed through the isthmotectal system that is aligned with the direct retinotectal projection. This alignment is mediated by an activitydependent process but there is no indication of competition between these two projections (Gaze et al., 1970; Udin and Keating, 1981; Udin, 1985).

In summary, we found that reducing the number of optic fibers to the point where there were many "vacant" synaptic sites had relatively little long-term effect on activity-mediated retinotopic refinement. Low synaptic density also did not prevent substantial activity-independent refinement but did produce partial inhibition. These results do not support a role for synaptic competition in activity-dependent refinement but could be taken to be compatible with such a role in activity-independent refinement, that is, chemoaffinity-directed growth. If synaptic competition plays a role in refinement, these results suggest it may play a greater role in activity-independent refinement than in activity-dependent refinement.

\section{References}

Antonian E, Perry GW, Grafstein B (1987) Fast axonally transported proteins in regenerating goldfish optic nerve: effect of abolishing electrophysiological activity with TTX. Brain Res 400:403-408.

Arnett DW (1978) Statistical dependence between neighboring retinal ganglion cells in goldfish. Exp Brain Res 32:49-53.

Edwards DL, Grafstein B (1984) Intraocular injections of tetrodotoxin in goldfish decreases fast axonal transport of $\left[{ }^{3} \mathrm{H}\right]$ glucosamine-labeled materials in optic axon. Brain Res 299:190-194.

Gaze RM, Sharma SC (1970) Axial differences in the reinnervation of the goldfish optic tectum by regenerating optic nerve fibers. Exp Brain Res 10:171-181.

Gaze RM, Keating MJ, Szekeley G, Beazley L (1970) Binocular interaction in the formation of specific intertectal neuronal connections. Proc R Soc Lond [Biol] 175:107-147.

Ginsburg KS, Johnsen JA, Levine MW (1984) Common noise in the firing of neighboring ganglion cells in goldfish retina. J Physiol (Lond) 351:433-450.

Harris WA (1980) The effect of eliminating impulse activity on the development of the retino-tectal projection in salamanders. J Comp Neurol 194:303-317.

Hayes WP, Meyer RL (1988a) Optic synapse number but not density is maintained during regeneration onto surgically-halved tectum in goldfish: HRP-EM evidence that optic fibers compete for fixed numbers of postsynaptic sites on tectum. J Comp Neurol 274:539-559.

Hayes WP, Meyer RL (1988b) Retinotopically inappropriate synapses of subnormal density formed by surgically misdirected optic fibers in goldfish tectum. Dev Brain Res 38:304-312.

Hayes WP, Meyer RL (1989a) Normal numbers of retinotectal synapses during the activity sensitive period of optic regeneration in goldfish: HRP-EM evidence implicating synapse rearrangement and collateral elimination during map refinement. J Neurosci 9:14001413.

Hayes WP, Meyer RL (1989b) Impulse blockade by intraocular tetrodotoxin during optic regeneration in goldfish: HRP-EM evidence that the formation of normal numbers of optic synapses and the elimination of exuberant optic fibers is activity independent. J Neurosci 9:1414-1423.

Hebb DO (1949) Organization of behavior. New York: Wiley

Hubel DH, Wiesel TN (1970) The period of susceptibility to the physiological effects of unilateral cyc closure in kittens. J Physiol (Lond) 206:419-436.

Hubel DH, Wiesel TN, LeVay S (1977) Plasticity of ocular dominance columns in the monkey striate cortex. Philos Trans R Soc Lond [Biol] 278:377-409.

Kageyama GH, Meyer RL (1988) Regenerating optic axons form transient topographically inappropriate synapses in goldfish tectum: a WGA-HRP EM study. Soc Neurosci Abstr 14:674.

Mesulam MM (1978) Tetramethyl benzidine for horseradish peroxidase neurohistochemistry: a non-carcinogenic blue reaction-product with superior sensitivity for visualizing neural afferents and efferents. J Histochem Cytochem 26:106-117.

Meyer RL (1977) Eye-in-water electrophysiology mapping of goldfish with and without tectal lesions. Exp Neurol 56:23-41.

Meyer RL (1978) Deflection of sclectcd optic fibers into a dencrvated tectum in goldfish. Brain Res 155:213-227.

Meyer RL (1980) Mapping the normal and regenerating retinotectal projection of goldfish with autoradiographic methods. J Comp Neurol 189:273-289.

Meyer RL (1982) Tetrodotoxin blocks the formation of ocular dominance columns in goldfish. Science 218:589-591.

Meyer RL (1983a) The growth and formation of ocular dominance columns by deflected optic fibers in goldfish. Dev Brain Res 6:279291.

Meyer RL (1983b) Tetrodotoxin inhibits the formation of refined retinotopography in goldfish. Dev Brain Res 6:293-298.

Meyer RL (1984) Target selection by surgically misdirected optic fibers in the tectum of goldfish. J Neurosci 4:234-250.

Meyer RL (1987) Tests for relabelling the goldfish tectum by optic fibers. Dev Brain Res 31:312-318.

Meyer RL, Kageyama GH (1988) Synaptic overlap followed by seg- 
regation of differentially labeled optic terminals in the goldfish optic tectum. Soc Neurosci Abstr 14:674.

Meyer RL, Wolcott LL (1987) Compression and expansion without impulse activity in the retinotectal projection of goldfish. J Neurobiol 6:549-567.

Meyer RL, Sakurai K, Schauwecker E (1985) Topography of regenerating optic fibers in goldfish traced with local wheat germ injections into retina: evidence for discontinuous microtopography in the retinotectal projection. J Comp Neurol 239:27-43.

Murray M, Edwards MA (1982) A quantitative study of the reinnervation of the goldfish optic tectum following optic nerve crush. $J$ Comp Neurol 209:363-373.

Murray M, Sharma S, Edwards MA (1982) Target regulation of synaptic number in the compressed retinotectal projection of goldfish. J Comp Neurol 209:374-385.

Olson MD, Meyer RL (199la) The effect of TTX-activity blockade and total darkness on the formation of retinotopy in the goldfish retinotectal projection. J Comp Neurol 303:412-423.

Olson MD, Meyer RL (1991b) Anatomical analysis of retinotopic refinement in a compressed retinotopic projection in goldfish with and without TTX activity blockade. Soc Neurosci Abstr 17:941.

Reh T, Constantine-Paton M (1985) Eye specific segregation requires neural activity in three-eye Rana pipens. I Neurosci 5:1132-1143.

Schmidt JT, Edwards DL (1983) Activity sharpens the map during the regeneration of the retinotectal projection in goldfish. Brain Res 269:29-39.

Schmidt JT, Cicerone CM, Easter SS (1978) Expansion of the half retinal projection to the tectum in goldfish: an electrophysiological and anatomical study. J Comp Neurol 177:257-278.
Shat CJ, Stryker MP (1988) Prenatal tetrodotoxin infusion blocks segregation of retinogeniculate afferents. Science 242:87-89.

Sperry RW (1963) Chemoaffinity in the orderly growth of nerve fiber patterns and connections. Proc Natl Acad Sci USA 50:703-710.

Stent GS (1973) A physiological mechanism for Hebb's postulate of learning. Proc Natl Acad Sci USA 70:997-1001.

Stryker MP, Harris WA (1986) Binocular impulse blockade prevents the formation of ocular dominance columns in cat visual cortex. $J$ Neurnsci 6:2117-2133

Swindale NV (1988) Role of visual experience in promoting segregation of eye dominance patches in the visual cortex of the cat. J Comp Neurol 267:472-488.

Udin SB (1985) The role of visual experience in the formation of binocular projections in frogs. Cell Mol Neurobiol 5:85-102.

Udin SB, Fawcett JW (1988) Formation of lopographic maps. Annu Rev Neurosci 11:289-327.

Udin SB, Gaze RM (1983) Expansion and retinotopic order in the goldfish retinotectal map after large retinal lesions. Exp Brain Res 50: 347-352.

Udin SB, Keating MJ (1981) Plasticity in a central nervous pathway in Xenopus: anatomical changes in the isthmo-tectal projection after larval eye rotation. J Comp Neurol 203:575-594.

Wang ZR, Meyer RL (1991) Retinotopic refinement of individual axonal arbors during optic nerve regeneration in goldfish with and without TTX activity. Soc Neurosci Abstr 17:40.

Yoon MG (1971) Reorganization of retinotectal projection following surgical operation on the optic tectum in goldfish. Exp Neurol 33: $395-411$. 